\title{
THE IMPORTANCE OF INCLUDING RECOGNITION OF PATTERNS ACTIVITIES IN LEARNING PROBLEM-SOLVING IN ENGINEERING CLASSROOMS
}

\author{
Shahad Abdulnour ${ }^{l}$, Wael L. Nackasha ${ }^{2}$, Cori Hanson ${ }^{1}$, and Thomas W. Coyle ${ }^{1}$ \\ ${ }^{1}$ Faculty of Applied Science and Engineering, University of Toronto, ${ }^{2}$ Osgoode Hall Law School, York University \\ shahad.abdulnour@utoronto.ca
}

\begin{abstract}
Why do we study limits?" "How would I calculate $7 \pi / 4$ without a calculator?" "There are several trigonometric formulas, how can I memorize them?" These are a few of the frequent questions asked by engineering students who seek the help of the Learning Strategist, a professional who advises students on academic skills. Attempting to memorize formulas and problem solutions without understanding their origin is common among engineering students. Consequently, students often disregard or are unaware of how formulas are derived, and they do not allocate time to find patterns that connect these formulas to the concepts they are learning in class. Investing time to study the origin and assumptions underlying formulas can be rewarding yet this process has a steep learning curve. Once mastered, understanding the derivation of commonly used formulas and mathematical patterns saves students' energy and time by giving them tools to quickly solve difficult engineering problems. In this paper, we demonstrate the process of problem-solving and pattern finding through a fun activity that can be utilized in lectures or tutorials to create in students an appreciation of the basics. The activity shows the importance of finding and understanding patterns and how to extend these findings into solutions. Through recognition of patterns, students can develop higher order thinking skills and the ability to derive formulas from their skeletal form. The goal of this project is to investigate the impact of instructors including pattern finding activities within their classrooms.
\end{abstract}

Keywords: Mathematics, Physical Sciences, ProblemSolving, Patterns, Formulas, Engineering Pedagogy

\section{INTRODUCTION}

Traditional teaching, specifically in mathematics and physical sciences, has been known for showing formulas and concepts without explaining the skeletal form such that "students frequently come to view mathematics as a collection of arbitrary rules, formulas, and algorithms handed down from teacher to student." [1] This is partially due to the fact that instructors need to cover a great amount of theory and concepts in a limited amount of time and therefore often do not include the derivation of formulas and their underlying patterns in class. Therefore, students may not gain an appreciation of the underlying analysis and the importance of derivation. Advanced formulas in their final forms, after going through several iterations and enhancement, are usually in a shape that can be applied to the textbook's examples. It is often not until graduate school or when working in industry that students realize that specific advanced forms of a formula might not be applicable, and they may need to rely on the basics to reconstruct another advanced formula.

Traditionally, instructors present theory and problems with the solutions in class. Students, then, are given problem sets to reflect what was taught in class. With this method of teaching, we are asking students to follow sets of rules and processes with the expectation that they will be tested on similar problems. As a result many students are not be able to solve questions that go beyond the sets of rules and require critical examination. This is not surprising when we consider that instructors have not concentrated on the patterns and the skeletal form of the formula and how we can solve other problems using the formula in its basic form. If students encounter new problems that were not presented in the problem-set, would they be able to think critically and find the right pattern to solve the question? This traditional approach is still common, and only slowly changing within engineering. The deficiency of this method of teaching has been acknowledged 30 years ago such that "Most mathematics lessons consist of teacher presentation of a "mathematical problem" along with the algorithm for solving it, followed by the assignment of a similar set of problems for students to work through individually at their seats." [2] Still, anecdotally, very little has changed, and we raise the same issue in this paper. In a nutshell, we are programming students to follow a specific path rather than helping them appreciate the dynamics behind the presented theory. 


\section{METHODOLOGY}

Engineering students at the Faculty of Applied Science and Engineering, University of Toronto were invited to a problem-solving workshop. We asked students questions regarding problem-solving and what it means to problemsolve at the beginning of the workshop. They were also asked about formulas and how to apply a formula. After the discussion, we did a visual activity where students were asked to study a whiteboard with patterns, letters, and numbers. The visual activity is depicted in Figure 1 below. After 15 seconds, the board was taken apart. Students were then asked to put the patterns, letters, and numbers back to their original locations.

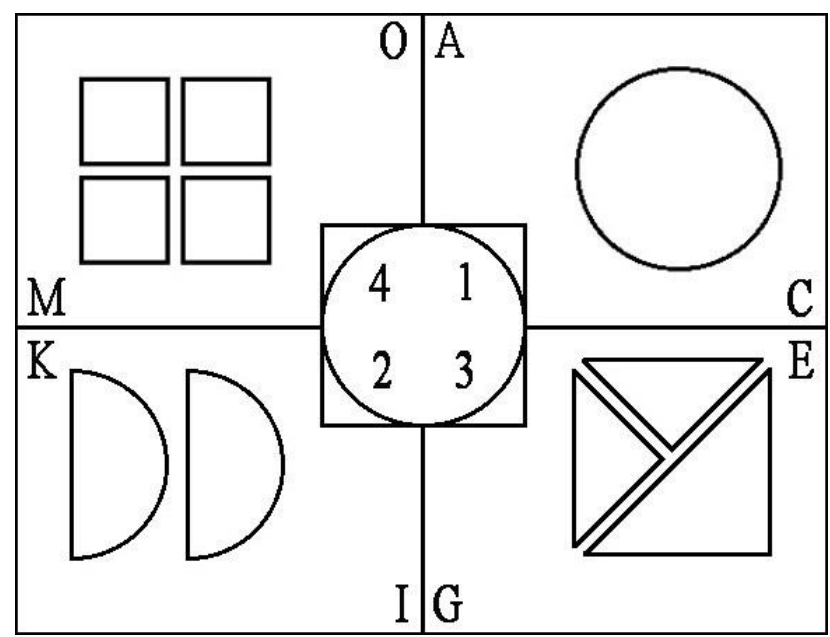

Fig. 1: A depiction of the visual activity used in the problem-solving workshop. This activity was inspired by a colleague, Tom Klubi, Learning Strategist and Program

Manager at Robert Gillespie Academic Skills Centre at the University of Toronto Mississauga.

A discussion followed on how this activity was related to understanding formulas. During this discussion, we worked through the process of how to find the area of a square through a formula, then we expanded this to the surface area of a cube, the area under a curve, and the area of irregular shapes. This led to a discussion of integration and the meaning behind the advanced formula. At the end of the workshop, participants were asked to provide feedback on whether this workshop was helpful and what stood out to them after working through this process. Participants were also asked how they felt about memorizing formulas.

\section{RESULT AND DISCUSSION}

One of the participants defined problem-solving as "using previous knowledge to work through new information and come to a reasonable conclusion." All students responded that when they saw a formula, they did not have time to derive it; they memorized it. Although a majority of our students agreed that understanding the foundation of the problem is crucial, they also agreed that understanding and deriving a formula takes a long time. There was a consensus that finding patterns among mathematical problems takes longer than memorizing specific solutions. They also often resort to "using the answer book more than sitting and problem-solving." When asked about the derivation of the problem itself, the majority answered that they "skim the derivation in the text and memorize the equation." Some of our students indicated that they are incapable or lack the knowledge to derive formulas and look for patterns while problem-solving or learning concepts.

When students memorize the derived formula without understanding the basics then they are likely not going to retain the information long term. Through the visual activity that was done in the workshop, it was evident to our students that understanding the basics helps retain information. Even if details of the theory were forgotten later on, through grasping and having a comprehensive understanding of the content, it would be much easier to recall the concepts.

Going through sets of blocks to come up with the basic formula for the area of a square was an eye-opener to some of our students. They had indicated that they had memorized length $x$ width since elementary school without thinking about it visually. Some students indicated that they did not put the forth the time and thought to reason through it. Taking this concept further to an advanced concept was effective and valuable to observe. The more advanced concepts became clearer and students better understood why a particular formula was being used because they understood how it was derived.

Through this workshop, it was brought to our attention that students have different backgrounds with different retention capabilities even though they, more or less, had similar grades when admitted to university. One student indicated that the calculus review session they attended in first year was not a review but rather new information that they were seeing for the first time.

Our students indicated that this workshop was very useful. One student said: "It will help me to better understand how much I truly know or what I have memorized. I will be able to step away from the equation in front of me and look for patterns. I like this workshop." Some also recognized that they can apply this not only to their mathematical courses but also to other courses. "There are so many equations, many not even talked about in class ... so knowing how to look for the repeating components will help a lot." If we can implement such activities during class, our students will appreciate the derivation of formulas. Through these results, it becomes evident that class time could and arguably should be enhanced and used for reasoning and showing patterns instead of walking students through solutions of problem sets and then expecting them to memorize the steps and reiterate the solutions back. 


\section{CONCLUSION}

We need to ask ourselves, are our students actually memorizing formulas, processes, and facts or are they critically thinking about mathematics and how these formulas can be applied in physical sciences and our world? Potentially, "the tasks used in mathematics classrooms highly influence the kinds of thinking processes in which students engage, which, in turn, influences student learning outcomes." [1] The findings from this pilot study show that encouraging critical thinking and reasoning in the classroom is an important part of learning math based courses. It is an awareness step. We hope that this work will help influence instructors to include mathematical reasoning and sense-making into their courses. In doing so provides students with the opportunity to learn these pattern recognition skills and practice solving problems in a more process driven way and not rely solely on memorization to succeed academically.

\section{References}

[1] Mary Kay Stein, Barbara W. Grover and Marjorie Henningsen, "Building student capacity for mathematical thinking and reasoning: an analysis of mathematical tasks used in reform classrooms," American Educational Research Journal, vol. 33 , no. 2 , pp. $455-88,1996$.

[2] Alan H. Schoenfeld, "Learning to think mathematically: Problem solving, metacognition, and sense-making in mathematics," D. Grouws (Ed.),Handbook for Research on Mathematics Teaching and Learning, pp. 334-370, 1992. 